\title{
Thermodynamic Analysis of Air-Blown Staged Gasification of Coal in a Flow
}

\author{
D.A. Svishchev*
}

Melentiev Energy Systems Institute of Siberian Branch of the Russian Academy of Sciences, Irkutsk, Russia

\begin{abstract}
One of the ways to environmentally friendly use coal is an integrated gasification combined cycle. The most common oxidizing agent employed in gasification is oxygen. It is feasible to use air instead of oxygen to reduce the cost of generated electricity. The air gasification downsides can be reduced by using heated air and organizing a staged process. The paper is concerned with a thermodynamic analysis of the MHPS (Mitsubishi Hitachi Power Systems) airblown staged gasifier. The analysis relies on an original approach that suggests investigating experimental data on a set of calculated ones. The experimental run nears the thermodynamic optimum, which coincides with the carbon boundary line. Cold gas efficiency can be increased from 78.6 to $81.5 \%$ by reducing the equivalence ratio. Thus, the temperature will decrease from 1200 to $1100{ }^{\circ} \mathrm{C}$. The experimental run of the MHPS gasifier is not optimal thermodynamically, but it is probably optimal kinetically. The fact is that the rates of heterophase reactions decline near the carbon boundary, which leads to a sharp increase in fuel underburning and a decrease in efficiency. The experimental run is also located close to the region with the maximum thermal efficiency of the process, which is indicative of the high efficiency of converting air heat into chemical energy of producer gas.
\end{abstract}

Index Terms: coal gasification, entrained-flow, thermodynamic modeling.

\footnotetext{
${ }^{*}$ Corresponding author.

E-mail: denis.svishchev@gmail.com
}

http://dx.doi.org/10.38028/esr.2021.03.0004

Received September 06, 2021. Revised September 30, 2021.

Accepted October 23, 2021. Available online November 28, 2021.

This is an open access article under a Creative Commons Attribution-NonCommercial 4.0 International License.

(C) 2021 ESI SB RAS and authors. All rights reserved.

\section{INTRODUCTION}

Gasification is the thermochemical fuel conversion, which involves gaseous oxidants, solid oxidants, or supercritical water $[1,2]$. The main product of this process is combustible gas used for energy purposes or as a chemical raw material. One of the main options for environmentally friendly use of fossil coal is the technology of its integrated gasification in combined cycle (IGCC) $[3,4]$. Most operating IGCCs include an entrained-flow gasifier operating on oxygen or its mixtures with steam (Table 1). Two large plants use air as a gasification agent. These are the Nakoso IGCC plant in Japan and Kemper Country energy facility in the USA. Such a small spread of this type of gasification agent is due to the following air gasification downsides:

- low degree of coal conversion in the reactor, which requires coke recycling;

- low heating value (LHV) of the produced gas and the related problem of its stable combustion in the combustion chamber of a gas turbine [5];

- relatively low cold gas efficiency of air gasification;

- the complexity of organizing the removal of liquid slag in comparison with the high-temperature oxygen process.

A significant advantage of air gasification is the absence of an air separation unit. It increases capital costs of the construction of a plant and auxiliary power supply. The relatively low gas temperature at the gasifier outlet makes it possible to use the high-temperature part of the recovery boiler for gas cooling.

Compressed air can be supplied to the gasifier from the turbine compressor. It heats up to $500{ }^{\circ} \mathrm{C}$ when compressed [10]. Further heating of air to $700-1000{ }^{\circ} \mathrm{C}$ can reduce the above air gasification disadvantages, thereby improving the gas heating value, the degree of coal conversion, and cold gas efficiency. Some researchers work on gasification with heated air [11-13]. These studies use biomass and wastes as fuel. 
TABLE 1. Characteristics of the main operating IGCCs [6-9].

\begin{tabular}{ccccc}
\hline \hline $\begin{array}{c}\text { Year } \\
\text { of commissioning }\end{array}$ & Plant & Country & Size, MWth & Gasifier type \\
\hline 1994 & Buggenum & Netherlands & 253 & Shell, entrained-flow \\
1995 & Wabash River & USA & 262 & E-Gas, two-stage entrained-flow \\
1996 & Tampa Polk & USA & 250 & Texaco, entrained-flow \\
1998 & Puertollano & Spain & 335 & PRENFLO, entrained-flow \\
2002 & Wakamatsu & Japan & 170 & EAGLen \\
2005 & Vresova & Czech & 400 & Lurgi, fixed-bed updraft \\
2007 & Nakoso & Japan & 250 & MHPS, two-stage entrained-flow \\
2014 & Kemper County & USA & 524 & TRIG, entrained-flow \\
\end{tabular}

Another method for improving air gasification is a staged organization of the process. Since 1981, the twostage air gasification technology has been developed by Mitsubishi Heavy Industries jointly with the CRI (Central Research Institute of Electric Power Industries) [5]. These organizations have developed and tested several gasifiers of various sizes. These are a demonstration stand with a capacity of 2.4 t/d (1983-1995, location of Yokosuka Lab.), a semi-industrial gasifier with a capacity of $200 \mathrm{t} / \mathrm{d}$ (19911995, the Nakoso station, Fukushima), and an industrial plant with a capacity of $1700 \mathrm{t} / \mathrm{d}$ (since 2007, Nakoso station) [14].

The paper aims to analyze the operation of the MHPS (Mitsubishi Hitachi Power Systems) gasifier. A thermodynamic analysis of this reactor was carried out earlier [10]. One-dimensional kinetic models were employed in numerical studies of the gasifier $[15,16]$. The current work is grounded on an original thermodynamic approach, which makes it possible to analyze one or several experimental conditions on a set of modeled ones, and allows:

- estimating the efficiency of reactor and outlining ways to improve it;

- identifying the constraints preventing process optimization;

- evaluating the influence of various process parameters in terms of thermodynamics to identify primary and secondary ones among them.

This approach was previously used to analyze the conditions of biomass downdraft gasification [17].

\section{METHODS AND APPROACHES}

\section{A. A thermodynamic model with macrokinetic} constraints

A thermodynamic model that factors in the equilibrium in a closed reaction system [18] was used for modeling the experimental run (Table 1). The model maximized the entropy of the system. The constant parameters were pressure and enthalpy. Equilibrium is referred to as a convex programming problem:

find

$$
\max S(x, T)=\sum_{j} S_{j}(x, T) x_{j}
$$

subject to

$$
\begin{aligned}
& \sum_{j=1}^{n} a_{i j} x_{j}=b_{i}, i=\overline{1, m}, \\
& x_{j} \geq 0, \forall j=\overline{1, n}, \\
& H_{h r}=\sum_{j} H_{j}\left(T^{i n}\right) x_{j}^{i n}-H, \\
& H=\sum_{j} H_{j}(T) x_{j}, \\
& x_{k} \geq \varphi\left(x, x^{i n}\right),
\end{aligned}
$$

where $S(x, T)$ is the total entropy of substances in the system and $S_{j}(x, T)$ is the specific entropy of substance. Index $j$ refers to substances, whereas index $i$ refers to chemical elements; $x=\left(x_{1}, \ldots, x_{n}\right)^{T}$ is the vector of substances amounts. Material balance is determined by equation (2), where $a_{i j}$ is the number of atoms of element $i$ in a molecule of substance $j ; b_{i}$ is the amount of substance of element $i$ in the system.

The energy balance of the system is found by equations (4) and (5), where $H(x, T)$ is the total system enthalpy, and $H_{j}(T)$ is the substance enthalpy; $H_{h r}$ is the heat exchange between the system and environment.

Expression (6) is a generalized macrokinetic constraint on the formation or response of a substance in the system [19]. The model takes into account the experimentally observed methane yield exceeding the equilibrium value with this constraint.

A software package consisting of two modules was implemented for calculations. The first module is a $\mathrm{C}++$ program used to calculate chemical equilibrium. The second module is written in PHP and is used to form a computational matrix, optimize process conditions, process and output data in a client-server application.

Cold gas efficiency (\%) is calculated as [20]:

$$
C G E=\frac{L H V_{\text {gas }} V_{\text {gas }}}{L H V_{\text {coal }} m_{\text {coal }}} 100,
$$

where $L H V_{\text {gas }}\left(\mathrm{kJ} / \mathrm{m}^{3}\right)$ and $L H V_{\text {coal }}(\mathrm{kJ} / \mathrm{kg})$ are the low heating values of gas and coal, respectively; $V_{\text {gas }}\left(\mathrm{m}^{3}\right)$ is the gas volume; $m_{\text {coal }}$ is the mass of coal. The thermal efficiency $(\%)$ of the process is calculated using equation (8), where $Q_{\text {air }}\left(\mathrm{kJ} / \mathrm{m}^{3}\right)$ and $V_{\text {air }}\left(\mathrm{m}^{3}\right)$ are the heat and the volume of air, respectively:

$$
T E=\frac{L H V_{\text {gas }} V_{\text {gas }}}{L H V_{\text {coal }} m_{\text {coal }}+Q_{\text {air }} V_{\text {air }}} 100,
$$


TABLE 2. MHPS gasifier testing results

\begin{tabular}{|c|c|c|}
\hline PARAMETER & VALUE & REF. \\
\hline COLD GAS EFFICIENCY, \% & 77.2 & [21] \\
\hline COAL CONVERSION DEGREE, $\%$ & 99.9 & {$[22]$} \\
\hline DRY GAS COMPOSITION, \% VOL. & & [22] \\
\hline $\mathrm{CO}$ & 30.5 & \\
\hline $\mathrm{CO}_{2}$ & 2.8 & \\
\hline $\mathrm{H}_{2}$ & 10.5 & \\
\hline $\mathrm{CH}_{4}$ & 0.7 & \\
\hline $\mathrm{N}_{2}$ AND OTHERS & 55.5 & \\
\hline PRODUCER GAS TEMPERATURE AT THE GASIFIER OUTLET, ${ }^{\circ} \mathrm{C}$ & 1200 & [23] \\
\hline GASIFYING AIR TEMPERATURE, ${ }^{\circ} \mathrm{C}$ & 500 & [10] \\
\hline $\begin{array}{l}\text { HEAT LOSS THROUGH THE REACTOR WALL, \% (OF COAL LOW HEATING } \\
\text { VALUE) }\end{array}$ & 2 & [10] \\
\hline REACTOR PRESSURE, MPA & 2 & [10] \\
\hline
\end{tabular}

Equivalence ratio (ER) is determined by equation (9) as the ratio of the actual amount of air $\left(V_{\text {air,actual }}, \mathrm{m}^{3}\right)$ to the amount required for complete (stoichiometric) combustion of coal $\left(V_{\text {aircomb }}, \mathrm{m}^{3}\right)$. In general, the equivalence ratio is characterized by the air/fuel ratio:

$$
E R=\frac{V_{\text {air }, \text { actual }}}{V_{\text {air }, \text { comb }}} .
$$

\section{B. Equilibrium model input data}

Data on a single start of the gasifier at the Nakoso plant with a capacity of $1700 \mathrm{t} / \mathrm{d}$ are shown in Table 2 . This experiment was carried out on Chinese coal with the following characteristics (\% mass): $C^{\text {daf }}: 82.00, H^{\text {daf }}$ : $4.86, O^{\text {daf }}: 12.05, N^{\text {daf }}: 0.92, S^{\text {daf }}: 0.17, A^{d}: 6.1, W^{r}: 5.6, V^{d}$ : 35.28 [10]. The high heating value of the coal was 30.2 $\mathrm{MJ} / \mathrm{kg}$ (dry).

The input data of the equilibrium model are the initial composition of the reaction system, the intensity of its heat exchange with the environment (or temperature), and pressure. The initial composition of the reaction system is set following the chemical composition of the coal and air, and the equivalence ratio. The last parameter is not given in open sources. To calculate it, one should make the mass balance in the experiment or find it using a thermodynamic model. The latter was used since it opens up additional possibilities for analyzing the gasifier operation.

We can use the redundancy of available experimental data to search for the equivalence ratio. The task is reduced to finding an equivalence ratio (air/fuel ratio) such that the process temperature is $1200{ }^{\circ} \mathrm{C}$, and the heat loss is $2 \%$, i.e., the temperature in the reactor rises with an increase in the air/fuel ratio and at a constant value of heat exchange. A decrease in this ratio leads to a decline in the reactor temperature. The temperature in the reactor will be $1200{ }^{\circ} \mathrm{C}$ for a particular value of the equivalence ratio.

\section{RESULTS AND DISCUSSION}

\section{A. Model verification.}

The equilibrium composition of reaction products is compared with the experimental one in Table 3. The producer gas temperature at the reactor outlet is 1200 ${ }^{\circ} \mathrm{C}$. Concentrations of gas components are numerically the same. The model underestimates the carbon dioxide yield by 1.1 percentage point and overestimates the cold gas efficiency accordingly. The closeness of the modeled yield of substances to the experimental one is due to the reaction conditions favoring the attainment of

TABLE 3. Comparison of modeled and experimental results.

\begin{tabular}{lcc}
\hline \hline Parameter & Experiment [21, 22] & Equilibrium \\
\hline Cold gas efficiency, \% & 77.2 & 78.6 \\
Equivalence ratio, - & n.d. & 0.406 \\
Coal conversion degree, \% & 99.9 & 100 \\
Dry gas composition, \% vol. & & 30.5 \\
$\mathrm{CO}$ & 30.5 & 1.7 \\
$\mathrm{CO}_{2}$ & 2.8 & 10.5 \\
$\mathrm{H}_{2}$ & 10.5 & 0.7 \\
$\mathrm{CH}_{4}$ & 0.7 & 56.7 \\
$\mathrm{~N}_{2}$ and others & 55.5 & 1200 \\
The gas temperature on the gasifier outlet, ${ }^{\circ} \mathrm{C}$ & 1200 & \\
\hline \hline
\end{tabular}


a close-to-equilibrium state by the chemical system. These are a sufficient residence time of substances in the reactor, high temperature, and pressure.

B. Analysis of the experimental run on a set of equilibrium data.

A set of possible operating conditions of the gasifier can be calculated by varying two model parameters. These are the equivalence ratio and the heat exchange between the reactor and the environment. The result of this calculation is shown in Fig. 1. The equivalence ratio is changed with a step of 0.01 , while heat exchange is altered with a step of $1 \%$ to accurately show the isolines in the Figure.

The isoline that reflects the zero equilibrium yield of the coke residue is called the carbon boundary line [17]. To the left of this line, a thermodynamically stable carbon residue is formed in the reacting system. Its yield increases to $0.1-0.4 \mathrm{~kg} / \mathrm{kg}$ (coal) as the equivalence ratio decreases, and the thermochemical conversion process shifts to pyrolysis (region A) in this case. The cold gas efficiency of the process is reduced because carbon residue does not convert to a combustible gas.

Thermodynamic conditions for complete fuel consumption should be to the right of the carbon line. The equivalence ratio increases and the conversion process goes to the combustion region (region B). In this case, excessive oxidation of the gas combustible components with air occurs. The efficiency of the process also decreases.

The conditions located on the carbon boundary line are characterized by the maximum cold gas efficiency attainable at a certain level of heat transfer between the reaction system and the environment [17]. The Figure also shows temperature isolines that limit the conversion area to an interval of $300-2000{ }^{\circ} \mathrm{C}$. Fuel does not ignite below $300{ }^{\circ} \mathrm{C}$. There is a problem with the thermal stability of structural materials of the reactor above $2000{ }^{\circ} \mathrm{C}$.

The experimental run of the MHPS reactor (point 1200 ${ }^{\circ} \mathrm{C}$ ) is not optimal from the thermodynamic point of view. It is located slightly to the right of the carbon boundary line but can be shifted to the boundary line when the equivalence ratio decreases to 0.384 and the temperature in the gasifier drops to $1100^{\circ} \mathrm{C}$. This action will increase the cold gas efficiency of the process from 78.6 to $81.5 \%$. Reaction system motion to the carbon boundary line, however, will considerably slow down the rates of the heterophase reactions between carbon residue and gas at the gasifier outlet [17]. This phenomenon is natural. The boundary line corresponds to equilibrium between a fuel (solid) phase and a gas phase. There is an insufficient difference in thermodynamic potentials for the occurrence of chemical reactions. The degree of fuel conversion in the test run was $99.9 \%$ (see Table 2). Optimization of this run towards a decrease in the equivalence ratio will lead to appreciable fuel underburning due to the kinetic limitations of the carbon residue reactions. The cold gas efficiency will also decline. The experimental operating conditions of the MHPS reactor are likely to prove optimal kinetically but not thermodynamically.

Apart from the equivalence ratio, the position of the experimental run relative to the carbon boundary line is influenced by the heat exchange between the reactor and the environment. It is equal to the sum of the heat losses of the reactor minus the amount of external heat input with heated air. Fig. 2 shows the isolines of thermal efficiency, which factors in the efficiency of converting both the coal chemical energy and the external heat supplied to gas

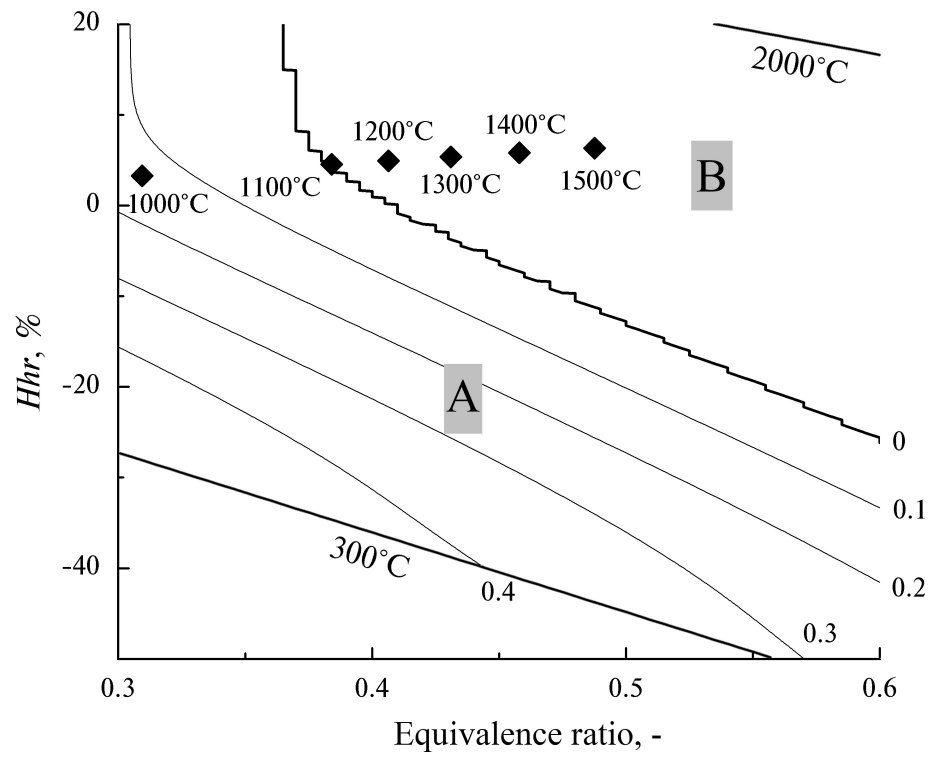

Fig. 1. Modeling the operating conditions of the MHPS gasifier. Isolines indicate the equilibrium yield of the carbon residue ( $\mathrm{kg} / \mathrm{kg}$ (coal)). The point $1200^{\circ} \mathrm{C}$ corresponds to the experiment [23]. The rest of the points are calculated for the indicated reactor temperatures. 


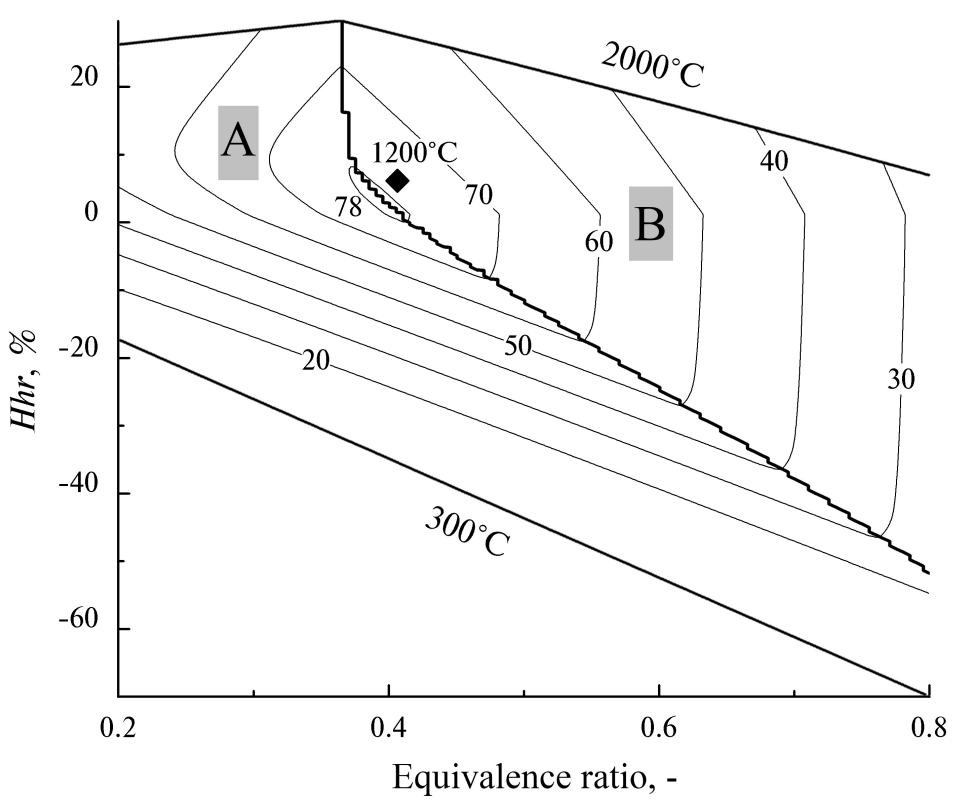

Fig. 2. Results of modeling the air gasification process in the MHPS reactor. Isolines indicate thermal efficiency levels. Diamond corresponds to the experimental run [23].

energy. Thermal efficiency is characterized by an optimum localized within the $78 \%$ isoline and equal to $79.2 \%$. The experimental run of the MHPS reactor is located near this optimum. External heat in the experiment is supplied with compressed air heated to $500{ }^{\circ} \mathrm{C}$.

\section{CONCLUSIONS}

The thermodynamically optimal gasification conditions are located near the carbon boundary line corresponding to the equilibrium between the gas and coke phases. Achievement of optimal conditions turns out to be kinetically limited. The free energy of the reaction system approaches the equilibrium value when nearing the carbon boundary. Such restrictions increase coke underburning and decrease cold gas efficiency of gasification.

As evidenced by the analysis performed, the MHPS gasifier operates in near-thermodynamically optimal conditions. Kinetic limitations turn out to be insignificant in this case. The fuel conversion rate is $99.9 \%$. These limitations can be removed by increasing the equivalence ratio relative to its optimal thermodynamic value.

\section{ACKNOWLEDGMENT}

The research was carried out under State Assignment Project (no. FWEU-2021-0005) of the Fundamental Research Program of the Russian Federation 2021-2030 using the resources of the High-Temperature Circuit Multi-Access Research Center (Ministry of Science and Higher Education of the Russian Federation, project no 13.CKP.21.0038).

Author thanks A.F. Ryzhkov for consulting on the MHPS gasifier operation.

\section{REFERENCES}

[1] M. Osman, M. N. Khan, A. Zaabout, S. Cloete, and S. Amini, "Review of pressurized chemical looping processes for power generation and chemical production with integrated $\mathrm{CO} 2$ capture," Fuel Processing Technology, vol. 214, p. 106684, Apr. 2021, DOI: 10.1016/j.fuproc.2020.106684.

[2] J. Chen et al., "Process in supercritical water gasification of coal: A review of fundamentals, mechanisms, catalysts and element transformation," Energy Conversion and Management, vol. 237 , p. 114122, Jun. 2021, DOI: 10.1016/j. enconman.2021.114122.

[3] S. Szima et al., "Finding synergy between renewables and coal: Flexible power and hydrogen production from advanced IGCC plants with integrated $\mathrm{CO} 2$ capture," Energy Conversion and Management, vol. 231, p. 113866, Mar. 2021, DOI: 10.1016/j. enconman.2021.113866.

[4] C. Xia, B. Ye, J. Jiang, and Y. Shu, "Prospect of nearzero-emission IGCC power plants to decarbonize coal-fired power generation in China: Implications from the GreenGen project," Journal of Cleaner Production, vol. 271, p. 122615, Oct. 2020, DOI: 10.1016/j.jclepro.2020.122615.

[5] S. Kaneko, "Current status on development of air blown two-stage entrained-flow coal gasifier," Fuel and Energy Abstracts, vol. 6, no. 37, p. 420, 1996.

[6] I. Barnes, "Recent operating experience and improvement of commercial IGCC," IEA Clean Coal Centre, London, UK, CCC/222, Aug. 2013.

[7] M. H. Sahraei, D. McCalden, R. Hughes, and L. A. Ricardez-Sandoval, "A survey on current advanced IGCC power plant technologies, sensors and control 
systems," Fuel, vol. 137, pp. 245-259, Aug. 2014, DOI: $10.1016 /$ j.fuel.2014.07.086.

[8] N. Nagasaki, K. Sasaki, T. Suzuki, S. Dodo, and F. Nagaremori, "Near-zero-emission IGCC power plant technology," Hitachi Review, vol. 62, no. 1, pp. 39-47, 2013.

[9] Q. Zhuang et al., "TRIGTM: An advanced gasification technology to utilize low-rank coals for power," Fuel, vol. 152, pp. 103-109, Jul. 2015, DOI: 10.1016/j. fuel.2014.12.011.

[10] A. Giuffrida, M. C. Romano, and G. Lozza, "Thermodynamic analysis of air-blown gasification for IGCC applications," Applied Energy, vol. 88, no. 11 , pp. $3949-3958$, Nov. 2011, DOI: $10.1016 /$ j. apenergy.2011.04.009.

[11] A. Ponzio, S. Kalisz, and W. Blasiak, "Effect of operating conditions on tar and gas composition in high-temperature air/steam gasification (HTAG) of plastic containing waste," Fuel Processing Technology, vol. 87, no. 3, pp. 223-233, Feb. 2006, DOI: 10.1016/j.fuproc.2005.08.002.

[12] J. Stasiek, M. Jewartowski, and W. Yang, "Small Scale Gasification of Biomass and Municipal Wastes for Heat and Electricity Production using HTAG Technology," E3S Web Conf., vol. 13, p. 03005, 2017, DOI: $10.1051 / \mathrm{e} 3$ sconf/20171303005.

[13] T. M. Ismail and M. A. El-Salam, "Parametric studies on biomass gasification process on updraft gasifier high-temperature air gasification," Applied Thermal Engineering, vol. 112, pp. 1460-1473, Feb. 2017, DOI: 10.1016/j.applthermaleng.2016.10.026.

[14] S. Hara, "Development of evaluation technology on various phenomena in coal gasifier," presented at the Second International Freiberg Conference on IGCC \& XtL Technologies, Freiberg, Saxony, Germany, May 8-12, 2007. [Online]. Available: https://tu-freiberg.de/sites/default/files/media/ institut-fuer-energieverfahrenstechnik-143/ publikationen/2007-5-4.pdf

[15] I. Donskoy, D. Svishchev, and A. Ryzhkov, "Reduced-Order Modeling of Pulverized Coal Staged Gasification: Influence of Primary and Secondary Fuel Proportion," Energy Systems Research, vol. 1, no. 4, pp. 27-35, Nov. 2018, DOI: 10.25729/ESR.2018.04.0003.

[16] I. G. Donskoy, “A Numerical Study of the Influence of Process Parameters on the Efficiency of Staged Coal Gasification Using Mixtures of Oxygen and Carbon Dioxide," Energy Systems Research, vol. 4, no. 2, pp. 27-34, Jul. 2021, DOI: 10.38028/ esr.2021.02.0003.

[17] D.A. Svishchev, A. N. Kozlov, I. G. Donskoy, and A. F. Ryzhkov, "A semi-empirical approach to the thermodynamic analysis of downdraft gasification," Fuel, vol. 168, pp. 91-106, 2016, DOI: 10.1016/j. fuel.2015.11.066.

[18] A. N. Gorban, Thermodynamic Equilibria and Extrema: Analysis of Attainability Regions andPartial
Equilibrium. Springer, 2006. [Online]. Available: https://books.google.ru/books?id=MXqKla_x5EQC

[19] I.G.Donskoy, V.A. Shamansky,A.N.Kozlov, andD.A. Svishchev, "Coal gasification process simulations using combined kinetic-thermodynamic models in one-dimensional approximation," Combustion Theory and Modelling, vol. 21, no. 3, pp. 529-559, Jan. 2017, DOI: 10.1080/13647830.2016.1259505.

[20] M. Shahabuddin and S. Bhattacharya, "Enhancement of performance and emission characteristics by cogasification of biomass and coal using an entrained flow gasifier," Journal of the Energy Institute, vol. 95, pp. 166-178, Apr. 2021, DOI: 10.1016/j. joei.2021.01.012.

[21] T. Hashimoto et al., "Development of IGCC commercial plant with air-blown gasifier," Mitsubishi Heavy Industries Technical Review, vol. 46, no. 2, pp. 1-5, Jun. 2009.

[22] M. Nunokawa, "Progress in NAKOSO $250 \mathrm{MW}$ air-blown IGCC demonstration project," presented at ICOPE-2013, Wuhan, China, Oct. 23-27, 2013. [Online]. Available: https://netl.doe.gov/sites/ default/files/2021-04/Nakoso\%20201310_ICOPE_ International_Conference_on_Power_Engineering. pdf

[23] H. Jaeger, "Japan 250 MW coal-based IGCC demo plant set for 2007 start-up," Gas Turbine World, vol. 35 , no. 2, pp. 12-16, 2005.

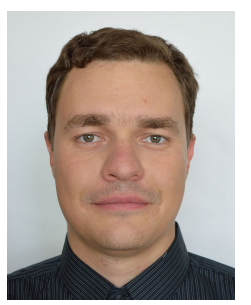

Denis Alekseevich Svishchev is a researcher in the Laboratory of Thermodynamics of Melentiev Energy Systems Institute SB RAS (Irkutsk). His research interests include thermophysical experiments, fuel processing, biomass combustion mechanisms, and thermodynamic modeling. 